\title{
Production and Characterization of Taxol as Anticancer Agent from Aspergillus terreus
}

\author{
Ashraf S.A. El-Sayed ${ }^{1 *}$ (D), Manal T. El Sayed ${ }^{1}$, Hend S. Nada², Abdallah E. Hassan ${ }^{3}$ \\ and Eman K. Yousef ${ }^{3}$ \\ ${ }^{1}$ Microbiology Department, Faculty of Science, Zagazig University, 44519, Egypt. ${ }^{2}$ Microbiology and Immunology \\ Department, Faculty of Veterinary Medicine, Zagazig University, 44519, Egypt. ${ }^{3}$ Chemistry Department, Faculty \\ of Science, Zagazig University, 44519, Egypt.
}

\begin{abstract}
Taxol, a diterpenoid was initially isolated from the bark of Taxus brevifolia, approved by FDA in 1994 as a powerful drug for metastatic ovarian carcinoma, breast and lung cancer. However, due to limitations in the production of this drug based on this plant source, the productive potentiality of fungi of this compound opened a new avenue for its commercial production. In this study, among the twenty fungal isolates screened for Taxol production, Aspergillus terreus had the highest potentiality to produce Taxol $(131.2 \mathrm{\mu g} / \mathrm{ml})$. The productivity of Taxol by $A$. terreus has been maximized by nutritional optimization using inhibitors and growth regulators. The yield of Taxol by $A$. terreus was maximally obtained $(0.663 \mu \mathrm{g} /$ $\mathrm{ml}$ ) by growing the fungal isolate on potato dextrose broth medium, amended with addition of biotin at $150 \mu \mathrm{g} / \mathrm{ml}$ for 20 days. The chemical structure Taxol extracted of $A$. terreus has been verified by proton and carbon NMR, IR and UV analyses. The activity of $A$. terreus Taxol has been assessed towards multiple cell lines, displaying a strong anticancer activity. In conclusion, the productivity of Taxol by $A$. terreus has been greatly improved upon using biotin as chemical modulator, that open a new avenue for commercializing the Taxol yield by fungi.
\end{abstract}

Keywords: Aspergillus terreus; Taxol; Nutritional optimization, Inhibitors.

*Correspondence: ash.elsayed@gmail.com

(Received: 18 September 2019; accepted: 19 October 2019)

Citation: Ashraf S.A. El-Sayed, Manal T. El Sayed, Hend S. Nada, Abdallah E. Hassan and Eman K. Yousef, Production and Characterization of Taxol as Anticancer Agent from Aspergillus terreus, J Pure Appl Microbiol., 2019; 13(4):2055-2063. https:// doi.org/10.22207/JPAM.13.4.17

(C) The Author(s) 2019. Open Access. This article is distributed under the terms of the Creative Commons Attribution 4.0 International License which permits unrestricted use, sharing, distribution, and reproduction in any medium, provided you give appropriate credit to the original author(s) and the source, provide a link to the Creative Commons license, and indicate if changes were made. 


\section{INTRODUCTION}

Taxol was firstly isolated and chemically identified by $\mathrm{X}$-rays crystallography from the bark of Pacific Yew trees (Taxus brevifolia) (Wani et al., 1971) and approved as a blockbuster anticancer drug for different cancerous types (Brown, 2003). The anticancer activity of Taxol arises from its specificity for binding with tubulin $\beta$-subunits, inducing tubulin polymerization, disrupting mitotic division of cancer cells (Straubinger et al., 1993). Although Taxol is produced from the bark of $T$. brevifolia, its tiny yield and vulnerability to unpredicted fluctuation with the ecological conditions were the major challenges to this approach (Malik et al., 2011; Wang et al., 2011). However, semisynthetic process of 10-deacetylbaccatin III (DAB) intermediates isolated from the European Yew (Taxus baccata) is the current approach for production of Taxol, but the heterogeneity of DAB yield with ecological conditions of $T$. baccata, the need for wide cultivation area and breading time are the major limitation (Thomas and Polwart, 2003). Alternatively, endophytic fungi from Taxus spp with powerful potency for Taxol production, unlocked a new rout to scale-up the Taxol yield, for their fast growth, cost effectiveness, independency on climat changes, possibility for growing on bulk fermenters, and feasibility for genetic manipulation (Stierle et al., 1993). With the higher applications of Taxol and its derivatives, the global demand of Taxol increases annually by approximately $10 \%$, thus, Taxol sources are the current challenge to sustain its global affordability (El-Sayed et al., 2017). Exploring of the fungal endophytes from Taxol producing and non-producing plants for ability to produce Taxol independent on their plant source and feasibility of metabolic manipulation raised the hope for industrial production of Taxol based on this technology. More than 250 endophytic fungal isolates were identified from T. baccata and about $20 \%$ of this population has the potentiality for Taxol production (Caruso et al., 2000; Flores-Bustamante et al., 2010). The biodiversity of fungal endophytes and their Taxol yield have been extensively reported (Strobel et al., 1996; El-Sayed et al., 2018a; Zein et al., 2019; El-Sayed et al., 2019; Artz et al., 2011). Frequent reports claimed the medicinal plants of ethnopharmacological relevance could provide a fertile source for different therapeutics (El-Sayed et al., 2019; El-Sayed et al., 2018). So, exploring novel endophytic fungi from medicinal plants with promising, sustainable potency for Taxol production is the eventual objective. Among the plants of medicinal relevance, Podocarpus spp with ethnopharmacological significance were traditionally used for their activity against bacterial and fungal pathogens, and for cancer treatment (Abdillahi et al., 2010; El-Sayed et al., 2019) . Thus, the objective of this study was to screen the potentiality of endophytic fungi recovered from different medicinal plants, to produce Taxol. As well as to optimize the Taxol yield by the potent fungal isolate using different chemical inhibitors.

\section{MATERIALS AND METHODS}

Isolation and culturing of the endophytic fungi

Different plant types were collected from Sharkia province, Egypt, during June-August/ 2018, as a source of endophytic fungal isolates. These plants were Zea mays, Solanum nigrum, Portulaco oleracea, Convalvulus arrensis, Ocimum basilicum, Erchharnia crassipes, Rosa sp, Citrus xaurantium, and Ricinus communis. The collected plant parts were cut into small segments $(5 \mathrm{~mm})$ with sterile sharp blade then washed by sterile distilled water and then sterilized with $70 \%$ ethanol $(\mathrm{v} / \mathrm{v})$ for 2 $\mathrm{min}$, then washed by $2.5 \%$ sodium hypochlorite $(\mathrm{NaOCl})$ and dried on sterile filter paper (Xiong et al., 2013). The plant parts were placed into the surface of potato dextrose agar (PDA) media with ampicillin $(1 \mu \mathrm{g} / \mathrm{ml})$ as antibacterial agent. The plates were incubated at $28^{\circ} \mathrm{C}$ for $5-10$ days. Sterile medium without plant segments was used as control to confirm the sterility of working area (El-Sayed et al., 2018). After incubation, the developed hyphal tips of the fungi were picked and purified on fresh PDA plates, incubated for 5-10 days at $28^{\circ} \mathrm{C}$, and the purified fungi were stored as slant culture at $4^{\circ} \mathrm{C}$ (Guo et al., 2008).

\section{Morphological and molecular identification of} the recovered endophytic fungi

The purified fungal isolates were examined based on their microscopical properties according to (Raper and Fennell, 1965). The potent Taxol producing endophytic fungi were further confirmed based on their ITS rDNA sequence (El-Sayed et al., 2019)(El-Sayed et al., 2013)(ElSayed et al., 2015). The PCR reaction contained 
$10 \mu$ l of 2' PCR master mixture (i-Taq ${ }^{\mathrm{TM}}$, Cat. \# 25027, iNtRON Biotech), $1 \mu$ l gDNA, forward and reverse primers $(10 \mathrm{pmol} / \mu \mathrm{l})$ and completed to $20 \mu l$. The PCR (Thermal Cycler 006, A\&E Lab Co) was programmed to initial denaturation $94^{\circ} \mathrm{C}$ for $2 \mathrm{~min}, 35 \mathrm{cycles}$ at denaturation $94^{\circ} \mathrm{C}$ for 20 $\mathrm{s}$, annealing $55^{\circ} \mathrm{C}$ for $30 \mathrm{~s}$, extension $72^{\circ} \mathrm{C}$ for 1 min, and final extension for $5 \mathrm{~min}$ at $72^{\circ} \mathrm{C}$. The PCR products were checked by $2 \%$ agarose gel in 1' TBE buffer normalizing to the DNA ladder. The amplicons were purified and sequenced using the same primer sets. The sequences were BLAST searched non-redundantly on NCBI database, and the phylogenetic tree of target sequence was constructed with MEGA 6.0 software (Tamura et al., 2011).

\section{Chromatographic and spectroscopic analyses of extracted Taxol}

The fungal cultures were grown on potato dextrose broth medium (PDB) (El-Sayed et al., 2012), after incubation of the fungal cultures, Taxol was extracted (El-Sayed et al., 2018 and 2019) and confirmed by TLC and HPLC. The extracted Taxol was analyzed by HPLC (Agilent Technology, G1315D) of C18 RP column (Eclipse Plus C18, $4.6 * 150 \mathrm{~mm})$, and methanol/ acetonitrile/water (25:35:40, v/v/v) as mobile phase, at flow rate $1 \mathrm{ml}$ /min for $25 \mathrm{~min}$ and injection volume $20 \mu \mathrm{l}$ (Nims et al., 2006). The fractions of Taxol were scanned from 200 to $500 \mathrm{~nm}$ by photoiodide array detector, the concentration and identity were determined from the retention time and absorption at $227 \mathrm{~nm}$.

The Taxol chemical structure of Taxol was confined by ${ }^{1} \mathrm{H}$ NMR, ${ }^{1} \mathrm{C}$ NMR spectra comparing to authentic Taxol (JEOL, ECA-500, $500 \mathrm{MHz} N \mathrm{NMR}$ ), samples were dissolved in Deuterated chloroform (CDCL3), and the chemical shifts were given in ppm with coupling constant expressed in hertz (El-Sayed et al., 2019).

The Infra-Red Spectra of extracted Taxol were analyzed using a JASCO, FTIR 6100 spectrophotometer. Samples of Taxol were ground in $\mathrm{KBr}$ pellets and pressed into discs by vacuum.

Nutritional optimization, and the effect of different inhibitors on Taxol yield

To investigate the optimal nutritional requirements of the potent fungi to maximize their Taxol yield, the influence of types of media in addition to the chemical inhibitors and activators were studied. The selected fungus was grown on Czapek's-Dox media (sucrose $30 \mathrm{~g} / \mathrm{L}$, sodium nitrate $2 \mathrm{~g} / \mathrm{L}, \mathrm{K}_{2} \mathrm{HPO}_{4} 1 \mathrm{~g} / \mathrm{L}, \mathrm{MgSO} 40.5 \mathrm{~g} / \mathrm{L}, \mathrm{KCl}$ $0.5 \mathrm{~g} / \mathrm{L}, \mathrm{FeSO} 40.01 \mathrm{~g} / \mathrm{L})$ (Onion's et al., 1981), Potato Dextrose Broth (PDB) (potato extract $250 \mathrm{~g}$, glucose $20 \mathrm{~g}$, dissolved in one liter distilled water) (El-Sayed et al., 2012), MID (El-Sayed et al., 2019), malt extract (El-Sayed et al., 2019) media.

The effect of different chemical compounds such as n-tosyl-I-phenylalanine, dinitro phenyl hydrazine, dimethylamino benzaldehyde, vitamin $B_{12}$, and biotin with different concentration (10 to $200 \mu \mathrm{g} / \mathrm{ml})$ on taxol production by the tested fungal isolate was evaluated. The cultures were filtered to remove any mycelia and Taxol was extracted as described above. The residues were re-dissolved in methanol and analyzed by chromatographic and spectroscopic methods, as mentioned above.

Antiproliferative activity of purified fungal Taxol The activity of extracted Taxol was evaluated against breast carcinoma (MCF7). Cells at $10^{3}-10^{5}$ per well were injected into the 96 -well plate, incubated for $24 \mathrm{hr}$. MTT reagent (Trevigen, Gaithersburg, USA) was added to each well, the plate was re-incubated for $2 \mathrm{hrs}$. Detergent reagent (Trevigen, Cat\# 4890-25-02) was added to wells, the plate was left in dark for $4 \mathrm{hrs}$ and then read at $570 \mathrm{~nm}$ in the plate reader. The average values of triplicates were determined and the average value for the blank was subtracted. The growth inhibition percentage was calculated using the formula percentage of cell inhibition $=100-\{($ At$A b) /(A c A b)\} \times 100$. Which, "At" is the O.D of test compound, " $A b$ " is O.D of blank, and " $A C$ " is O.D of control.

\section{Statistical Analysis}

All experiments were conducted in biological triplicates and the results were expressed by mean \pm STDEV. The data were analyzed by one-way ANOVA with Fisher's Least Significant Difference of post hoc test.

\section{RESULTS AND DISCUSSION \\ Isolation and identification of the endophytic fungal isolates}

Twenty fungal isolates were isolated and recovered as endophytes inhabiting the plants Zea mays, Solanum nigrum, Portulaco oleracea, Convalvulus arrensis, Ocimum basilicum, Erchharnia crassipes, Rosa sp, Citrus xaurantium, 
Ricinus communis. Morphologically, the purified endophytic fungal isolates were identified according to universal keys. These fungal isolates were belonging to three genera; Aspergillus, Fusarium, Penicillium. Aspergillus represents seventeen isolates; $A$. flavipes (no.1), A. niger (no.5), A. terreus (no.3), A. flavus (no.7). Fusarium represented by two isolates ( $F$. solani and $F$. oxysporum) and penicillium represents one isolate (P. chrysogenum) as shown in Table 1.

\section{Spectroscopic and Thin layer chromatography} analyses of extracted Taxol

The extracted Taxol from twenty fungal isolates was measured at wavelength $227 \mathrm{~nm}$. Among these isolates, only eight fungal isolates displayed positive results, giving maximum absorption at $د 227 \mathrm{~nm}$, similar to authentic Taxol (Table 1). To confirm the spectroscopic assay, the samples were spotted on TLC chromatography comparing to authentic Taxol as described in
Materials and Methods. The eight fungal isolates namely $A$. flavipes, A.flavus1, $A$. flavus 2, $A$. flavus 6, $A$. terreus 1, A. terreus 2, A. terreus 3, $P$. chrysogenum showed distinct spot under UV illumination at $254 \mathrm{~nm}$ with $\mathrm{Rf}$ value 0.7 which was identical to authentic taxol as showed in Fig. 1 , with bluish spot when TLC sheets sprayed with vanillin/ sulphuric acid reagent. From these fungal isolates, $A$. terreus 1 displayed the highest yield of Taxol $(131.7 \mu \mathrm{g} / \mathrm{ml})$ and the potent taxol spot.

\section{HPLC, NMR and IR analyses of extracted Taxol}

To investigate the presence of Taxol, fungal Taxol and authentic Taxol were subjected to HPLC analysis where authentic Taxol gave a peak with a retention time $1.8 \mathrm{~min}$ similar to fungal Taxol which gave a peak with retention time $1.89 \mathrm{~min}$ (Fig. 2). For further confirmation of the chemical structure of Taxol, the ${ }^{1} \mathrm{H}$ NMR analysis was performed where the signals of ${ }^{1} \mathrm{H} N M R$ for the fungal extract was found to be consistent to

Table 1. Spectroscopic and chromatographic analyses of the twenty fungal isolates

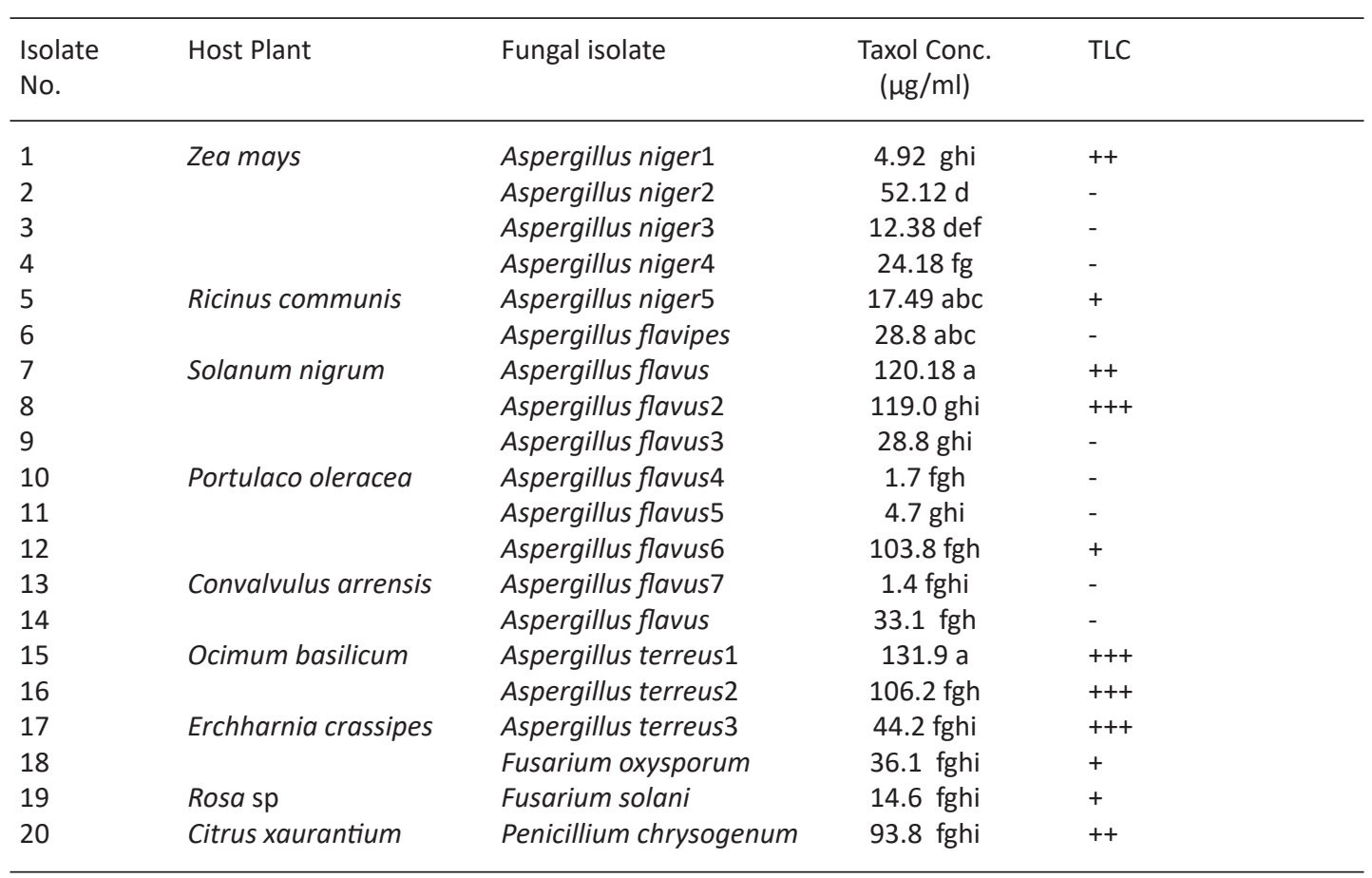

- Negative Taxol producer, + Mild Taxol producer, ++ Higher Taxol producer, +++ Strong Taxol producer values given are means

- The mean values followed by different letters $a, b, c$ with in the same column are significantly different (ONE Way ANOVA, Tukey HSD test, $\mathrm{p} \leq 0.05$ ).

$* * *$ means highly significant.

-LSD: the least significant difference. 
the authentic taxol, the signals were distributed at 1.0 and $8.0 \mathrm{ppm}$. The proton signals appeared in the region between 1.0 and $2.5 \mathrm{ppm}$ matching to methyl, acetate and acetylene groups (Kumaran et al., 2008; El-Sayed et al., 2019). Signals of most of protons in the taxane skeleton and their side chains protons were appeared in the region between 2.0 and $7.0 \mathrm{ppm}$ while the signals for aromatic moieties corresponding to the benzoate (2-OCOph), phenyl (C3'-ph) and benzamide (3' $\mathrm{NH}$ COph) groups were determined at 7.0 and $8.4 \mathrm{ppm}$ (Chmurny et al., 1992; Zhang et al., 2009; Strobel et al., 1996).
FT-IR analysis, Taxol of $A$. terreus displayed similar FT-IR peaks of standard Taxol as shown in Fig. 2. The peaks at 3406 and $3393 \mathrm{~cm}^{-1}$ were assigned for hydroxyl $(\mathrm{OH})$ and amide $( \pm \mathrm{C}(\mathrm{O})$ $\mathrm{NH} \pm$ ) groups stretch (Kumaran et al., 2008). However, the peaks at 2923, 1729 and $1604 \mathrm{~cm}^{-1}$ were assigned to the aliphatic $\mathrm{CH}$ stretch, ester groups stretch and aromatic rings stretch (Das et al., 2017). The COO stretching frequency was peaked at $1268 \mathrm{~cm}^{-1}$, while the peak at $1029 \mathrm{~cm}^{-1}$ was allocated for the aromatic $\mathrm{C}, \mathrm{H}$ bends.

Table 2. Effect of different chemical compounds on Taxol yield by A. terreus

\begin{tabular}{|c|c|c|c|c|}
\hline Compound & $\begin{array}{l}\text { Conc. } \\
(\mu \mathrm{g} / \mathrm{ml})\end{array}$ & $\begin{array}{c}\text { Taxol conc. } \\
(\mu \mathrm{g} / \mathrm{ml})\end{array}$ & TLC & $\begin{array}{l}\text { Increasing } \\
\text { fold }\end{array}$ \\
\hline Control & 0 & $163.9 \pm 9.6 \mathrm{ghi}$ & & - \\
\hline$N$-tosyl-L- & 10 & $286.9 \pm 344^{\text {efgh }}$ & + & 1.7 \\
\hline phenyl & 50 & $215.7 \pm 5.6^{\mathrm{fghi}}$ & + & 1.3 \\
\hline \multirow[t]{3}{*}{ alanine } & 100 & $331.8 \pm 1.7$ def & + & 2 \\
\hline & 150 & $162.3 \pm 3.7^{\mathrm{hi}}$ & - & - \\
\hline & 200 & $318.5 \pm 2.4$ ef $^{-1}$ & + & 1.94 \\
\hline Dinitrophenyl & 10 & $375.8 \pm 11.6^{\text {cde }}$ & + & 2.29 \\
\hline \multirow{4}{*}{ hydrazine } & 50 & $307.6 \pm 75.2$ efg & + & 1.87 \\
\hline & 100 & $605.6 \pm 2.8^{a b}$ & +++ & 3.6 \\
\hline & 150 & $471.5 \pm 2.5 \mathrm{bcd}$ & ++ & 2.8 \\
\hline & 200 & $128.1 \pm 8.4^{i}$ & - & - \\
\hline Dimethyl amino & 10 & $376.6 \pm 8.9$ cde & + & 2.29 \\
\hline \multirow[t]{4}{*}{ benzaldehyde } & 50 & $570.8 \pm 42.6$ ab & ++ & 3.48 \\
\hline & 100 & $514.2 \pm 7.5^{b c}$ & ++ & 3.13 \\
\hline & 150 & $341.4 \pm 7.4$ def & + & 2.08 \\
\hline & 200 & $320.9 \pm 6.4^{\text {ef }}$ & + & 1.95 \\
\hline \multirow[t]{5}{*}{ Vitamin B12 } & 10 & $379.7 \pm 71.2$ cde & - & 2.3 \\
\hline & 50 & $571.8 \pm 90.5^{\mathrm{ab}}$ & ++ & 4.17 \\
\hline & 100 & $510.5 \pm 95.5^{b c}$ & ++ & 3.11 \\
\hline & 150 & $343.4 \pm 11.61$ def & + & 2.8 \\
\hline & 200 & $325.8 \pm 68.9$ ef & + & 1.98 \\
\hline \multirow[t]{5}{*}{ Biotin } & 10 & $361.6 \pm 63.5^{\mathrm{de}}$ & + & 2.2 \\
\hline & 50 & $347.6 \pm 85.9$ def & + & 2.2 \\
\hline & 100 & $410.8 \pm 22.9$ cde & ++ & 2.5 \\
\hline & 150 & $663.8 \pm 0.57^{a}$ & +++ & 4.04 \\
\hline & 200 & $476.7 \pm 76.8^{\mathrm{bcd}}$ & +++ & 2.9 \\
\hline$P$ & - & $* * *(0.0000)$ & & \\
\hline $\operatorname{LSD}_{0.05}$ & - & 74.88 & & \\
\hline
\end{tabular}

-values given are means

- The mean values followed by different letters $a, b, c$ with in the same column are significantly different (ONE Way ANOVA, Tukey HSD test, $\mathrm{p} \leq 0.05$ ).

*** means highly significant .

-LSD: the least significant difference. 
Nutritional optimization of Aspergillus terreus to maximize their Taxol yield

Different types of media

Aspergillus terreus was cultivated on different media (PDB, MID, DOX, Malt extract). From the obtained results (Fig. 3), A. terreus gave the highest Taxol yield by growing on PDB media $(132 \mu \mathrm{g} / \mathrm{ml})$ followed by malt extract media
$(128.47 \mu \mathrm{g} / \mathrm{ml})$, with distinct corresponding Taxol spots on the TLC plates. However, the yield of Taxol by $A$. terreus was significantly low, with undetectable spots on TLC plates, under the standard conditions by growing on Czapek's-Dox and MID media. Consistently, PDB supports the maximum Taxol yield by $A$. terreus (El-Sayed et al., 2018b) and A. flavipes (El-Sayed et al., 2019a).

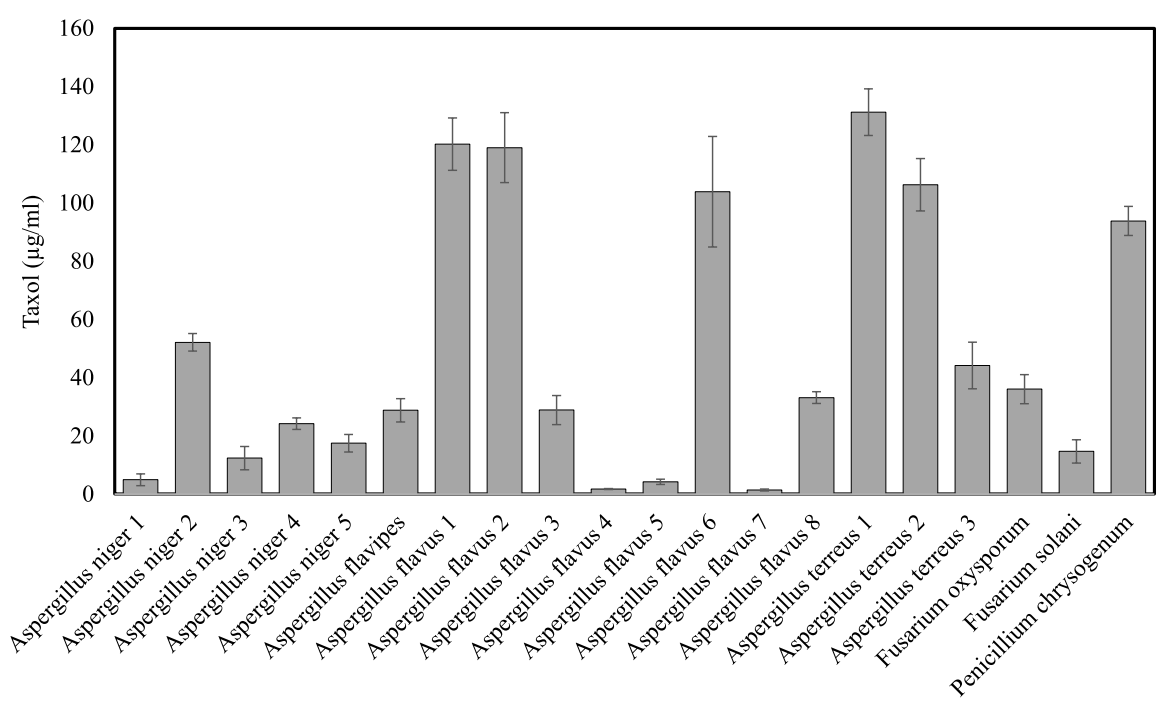

Fig. 1. Screening for Taxol producing potency among the recovered endophytic fungi

A

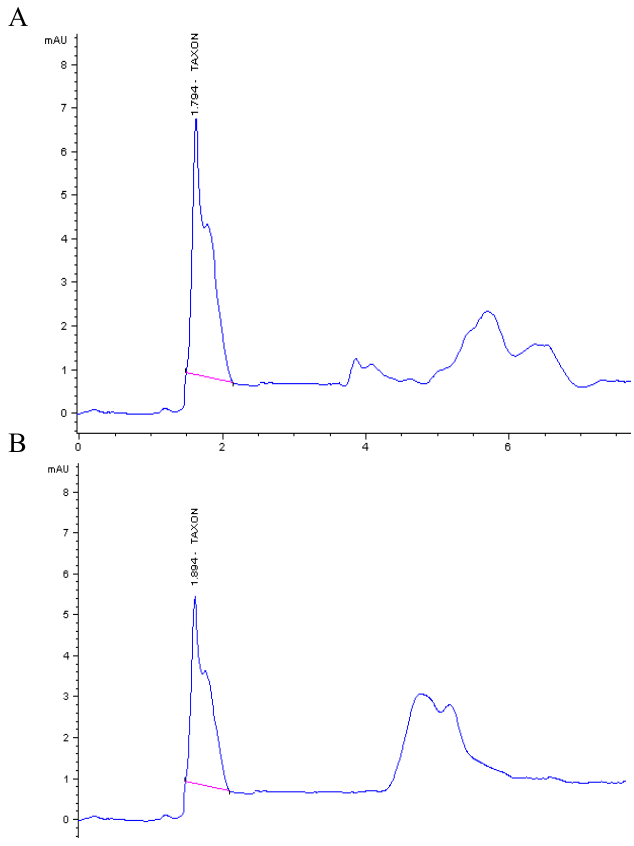

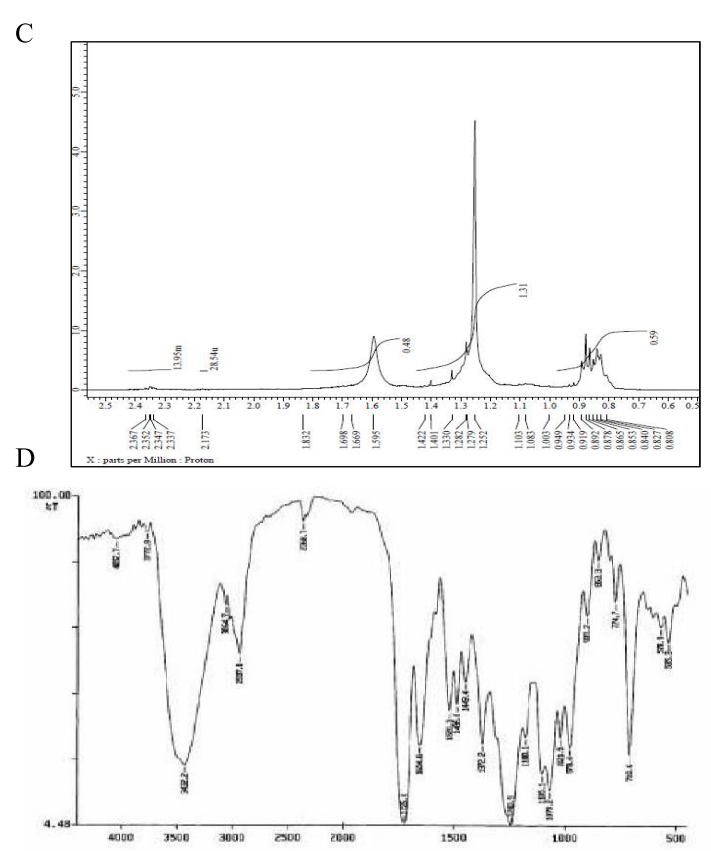

Fig. 2. Chromatographic and Spectral analyses of the extracted Taxol from A. terreus. HPLC chromatogram of authentic Taxol. (A), A. terreus extracted Taxol (B). NMR spectrum (C) and FT-IR spectrum (D) of A. terreus Taxol 

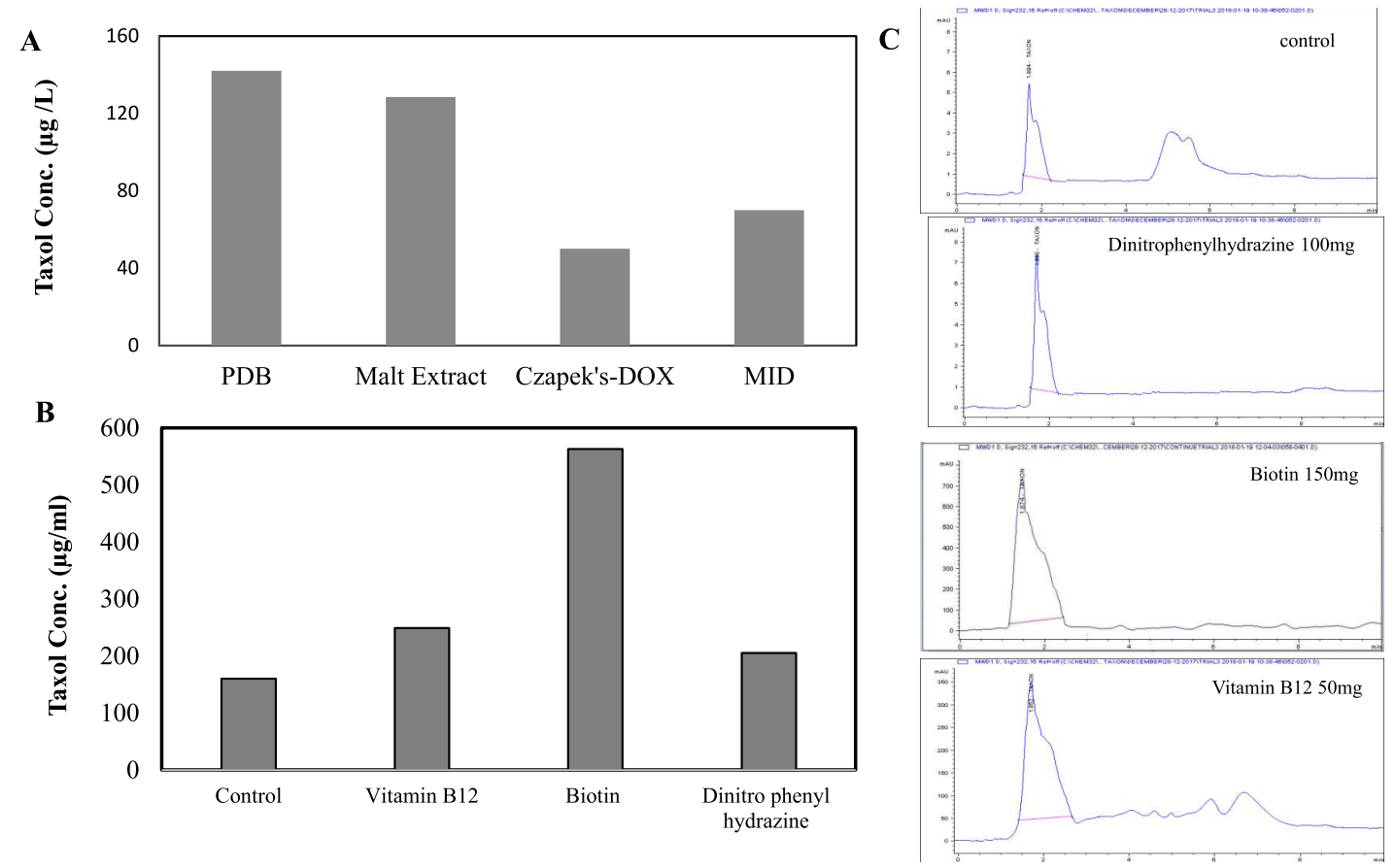

Fig. 3. Taxol yield of $A$. terreus by growing on different types of media and in response to different growth inhibitors. A, The fungal isolate was grown on different potato dextrose broth, malt extract, Czapek's-Dox and MID media (EISayed et al, 2018), and the Taxol was extracted and determined by HPLC. The cultures of $A$. terreus were amended with different inhibitors, incubated at standard conditions, then Taxol was extracted and quantified (B) from HPLC chromatogram (C).

\section{Different chemical compounds}

The effect of various inhibitors such as $N$-p-tosyl-I-phenylalanine, dinitrophenylhydrazine, dimethyl amino benzaldehyde, vitamin B12, Biotin at different concentration $(10,50$, $100,150,200 \mu \mathrm{g} / \mathrm{ml}$ ) on Taxol production by $A$. terreus was evaluated. The fungal cultures were cultivated with each compound on PDB medium for 15 days at $28^{\circ} \mathrm{C}$, then the Taxol yield was determined. From the results of UV spectroscopy and TLC chromatography, the Taxol yield by $A$. terreus in presence of biotin $(150 \mu \mathrm{g} / \mathrm{ml})$, vitamin B12 $(150 \mu \mathrm{g} / \mathrm{ml})$ and dinitrophenyl-hydrazine $(100 \mu \mathrm{g} / \mathrm{ml})$ was significantly increased by about 3.5, 3.5 and 4.1 folds, respectively, comparing to control (Table 2 ), with $p$ value was $<0.0001$. Thus, among the tested compounds, biotin displayed a significant inducing activity on Taxol yield by A. terreus by about 4.1 folds. The Taxol yield by A. terreus was slightly increased in presence of vitamin $B_{12}$, dimethylamino benzaldehyde and dinitrophenyl hydrazine at $10 \mu \mathrm{g} / \mathrm{ml}$ comparing to control. The taxol yield by $A$. terreus in response to

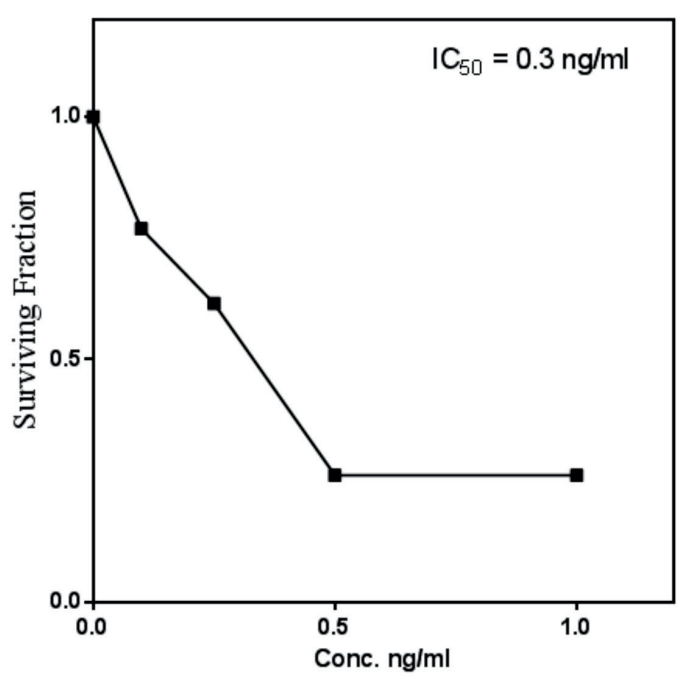

Fig. 4. Antiproliferative activity of extracted Taxol from A. terreus towards MCF-7 breast cell lines in vitro.

these inhibitors was authenticated from the HPLC analysis (Fig. 4). From the obtained results, the Taxol yield by $A$. terreus was maximally increased 
by incorporation of biotin, vitamin B12, and dinitrophenylhydrazine by 5, 2.2 and 1.6 folds, respectively, comparing to control.

\section{Antiproliferative activity using MTT test}

The antiproliferative activity of $A$. terreus Taxol was evaluated against MCF7-E (breast cancer cell). The IC ${ }_{50}$ value of $A$. terreus Taxol was $0.3 \mathrm{ng} / \mathrm{ml}$ towards MCF7-E (Fig. 4). The activity of extracted Taxol was noticed to be a dose-dependent manner towards the tested cell line. Coincident results authenticating the antiproliferative activity of $A$. terreus Taxol was documented in our previous studies (El-Sayed et al., 2019c; El-Sayed et al., 2018a and Zein et al., 2019).

\section{CONCLUSION}

Aspergillus terreus an endophyte of Ocimum basilicum displayed the highest potency for Taxol production, among the recovered endophytic fungal isolates from different medicinal plants. The yield of Taxol from A. terreus has been increased by about 4 folds upon addition of biotin at $150 \mu \mathrm{g} / \mathrm{ml}$ to the culture media after 5 days of cultural pre-incubation. The chemical identity of the extracted Taxol was validated by HPLC and spectroscopic analysis, as well as their anticancer activity was emphasized towards the MCF-7, regarding to authentic Taxol.

\section{ACKNOWLEDGEMENTS}

We appreciate the partial financial support from Zagazig University, and facilities at Enzymology and Fungal Biotechnology Lab, at Faculty of Science, Zagazig University, Egypt.

\section{CONFLICT OF INTEREST} conflict of interest.

The authors declare that there is no

\section{AUTHOR CONTRIBUTIONS}

ASAE and AEH designed and wrote the manuscript; MTE and HSN revise and edit the manuscript, EKY perform the experiments.

\section{FUNDING}

We appreciate the partial financial support (Grant \# EBFL2018019) from Botany and Microbiology Department, Faculty of Science, Zagazig University, Egypt.

\section{ETHICS STATEMENT}

The study was conducted ethically in accordance with the World Medical Association Declaration of Helsinki.

\section{DATA AVAILABILITY}

The raw data required to reproduce these findings are available to download from https:// www.researchgate.net/profile/Ashraf_El_Sayed.

\section{REFERENCES}

1. Abdillahi, H.S., Stafford, G.I., Finnie, J.F., and Van Staden, J. Ethnobotany, phytochemistry and pharmacology of Podocarpus sensu latissimo (s.l.). South African Journal of Botany, 2010; 76: 1-24. https://doi.org/10.1016/j.sajb.2009.09.002

2. Artz, J.D., Wernimont, A.K., Dunford, J.E., Schapira, M., Dong, A., Zhao, Y., et al. Molecular characterization of a novel geranylgeranyl pyrophosphate synthase from Plasmodium parasites. Journal of Biological Chemistry, 2011; 286: 3315-3322. https://doi.org/10.1074/jbc. M109.027235

3. Brown, D. Preclinical and clinical studies of the taxanes. In: Itokawa, H and Lee, K-H (eds) Taxus - The Genus Taxus, 2003.

4. Caruso, M., Colombo, A.L., Fedeli, L., Pavesi, A., Quaroni, S., Saracchi, M., and Ventrella, G. Isolation of endophytic fungi and Actinomycetes taxane producers. Annals of Microbiology, 2000; 50: 3-13.

5. Costat: Version 6.311, copyright (c), Cohort Software, 798 lighthouse Ave. PMB 320, Monterey, CA, 93940, USA, 2005.

6. Chmurny, G.N., Hilton, B.D., Brobst, S., Look, S.A., Witherup, K.M., and Beutler, J.A. ${ }^{1} \mathrm{H}$ - and ${ }^{13} \mathrm{C}-\mathrm{NMR}$ Assignments for Taxol, 7-epi-Taxol, and Cephalomannine. Journal of Natural Products, 1992; 55: 414-423. https://doi.org/10.1021/np50082a002

7. Das, A., Rahman, M.I., Ferdous, A.S., Amin, A.-, Rahman, M., Nahar, N., et al. An endophytic Basidiomycete, Grammothele lineata, isolated from Corchorus olitorius, produces paclitaxel that shows cytotoxicity, 2017; 1-17. https://doi.org/10.1371/ journal.pone.0178612

8. El-Sayed, A.S.A. L-methioninase production by Aspergillus flavipes under solid-state fermentation. Journal of Basic Microbiology, 2009; 49: 331-341. https://doi.org/10.1002/jobm.200800318

9. El-Sayed, A.S.A., Abdel-Ghany, S.E., and Ali, G.S. Genome editing approaches: manipulating of lovastatin and taxol synthesis of filamentous fungi by CRISPR/Cas9 system. Applied Microbiology and Biotechnology, 2017; 101: 3953-3976. https://doi. org/10.1007/s00253-017-8263-z

10. El-Sayed, A.S.A., Ali, D.M.I., Yassin, M.A., Zayed, R.A., and Ali, G.S. Sterol inhibitor "Fluconazole" enhance the Taxol yield and molecular expression of its encoding genes cluster from Aspergillus flavipes. Process Biochemistry, 2019; 76: 55-67. https://doi. org/10.1016/j.procbio.2018.10.008 
11. El-Sayed, A.S.A., Hassan, M.N., and Nada, H.M.S. Purification, immobilization, and biochemical characterization of I-arginine deiminase from thermophilic Aspergillus fumigatus KJ434941: Anticancer activity in vitro. Biotechnology Progress, 2015; 31. https://doi.org/10.1002/btpr.2045

12. El-Sayed, A.S.A., Mohamed, N.Z., Safan, S., Yassin, M.A., Shaban, L., Shindia, A.A., et al. Restoring the Taxol biosynthetic machinery of Aspergillus terreus by Podocarpus gracilior Pilger microbiome, with retrieving the ribosome biogenesis proteins of WD40 superfamily. Scientific Reports, 2019; 9: 11534. https:// doi.org/10.1038/s41598-019-47816-y

13. El-Sayed, A.S.A., Safan, S., Mohamed, N.Z., Shaban, L., Ali, G.S., and Sitohy, M.Z. Induction of Taxol biosynthesis by Aspergillus terreus, endophyte of Podocarpus gracilior Pilger, upon intimate interaction with the plant endogenous microbes. Process Biochemistry, 2018; 71: 31-40. https://doi. org/10.1016/j.procbio.2018.04.020

14. El-Sayed, A.S.A., Shindia, A.A., AbouZaid, A.A., Yassin, A.M., Shad Ali, G., and Sitohy, M.Z. Biochemical characterization of peptidylarginine deiminaselike orthologs from thermotolerant Emericella dentata and Aspergillus nidulans. Enzyme and Microbial Technology, 2019. https://doi.org/10.1016/j. enzmictec.2019.02.004

15. Flores-Bustamante, Z.R., Rivera-Orduna, F.N., Martinez-Cardenas, A., and Flores-Cotera, L.B. Microbial paclitaxel: advances and perspectives. The Journal of Antibiotics, 2010; 63: 460-467. https://doi. org/10.1038/ja.2010.83

16. Guo, B., Wang, Y., Sun, X., and Tang, K. Bioactive natural products from endophytes: A review. Applied Biochemistry and Microbiology, 2008; 44: 136-142. https://doi.org/10.1134/S0003683808020026

17. Khalaf, S.A and El-Sayed, A.S.A. I-Methioninase Production by Filamentous Fungi: I-Screening and Optimization Under Submerged Conditions. Current Microbiology, 2009; 58: 219-226. https://doi. org/10.1007/s00284-008-9311-9

18. Kumaran, R.S., Muthumary, J. and Hur, B.K. Production of taxol from Phyllosticta spinarum, an endophytic fungus of Cupressus sp. Engineering in Life Sciences, 2008; 8: 438-446. https://doi.org/10.1002/ elsc.200800019

19. Malik, S., Cusido, R.M., Mirjalili, M.H., Moyano, E., Palazon, J. and Bonfill, M. Production of the anticancer drug taxol in Taxus baccata suspension cultures: A review. Process Biochemistry, 2011; 46: 23-34. https:// doi.org/10.1016/j.procbio.2010.09.004

20. Nims, E., Dubois, C.P., Roberts, S.C., and Walker, E.L. Expression profiling of genes involved in paclitaxel biosynthesis for targeted metabolic engineering. Metabolic Engineering, 2006; 8: 385-394. https://doi. org/10.1016/j.ymben.2006.04.001

21. Raper, K.B. and Fennell, D.I. The Genus Aspergillus. Williams and Wilkins, 1965.

22. Stierle, A., Strobel, G., and Stierle, D. Taxol and taxane production by Taxomyces andreanae, an endophytic fungus of Pacific yew. Science, 1993; 260: https://doi. org/10.1126/science.8097061

23. Straubinger, R.M., Sharma, A., Murray, M., and Mayhew, E. Novel Taxol formulations; Taxol-containing liposomes. Journal National Cancer Institute Monographs, 1993; 69-78.

24. Strobel, G., Yang, X., Sears, J., Kramer, R., Sidhu, R.S., Hess, W.M., and Young, B. Endophytic fungus of Taxus wallachiana. Microbiology, 1996; 142: 3-8. https:// doi.org/10.1099/13500872-142-2-435

25. Tamura, K., Peterson, D., Peterson, N., Stecher, G., Nei, M., and Kumar, S. MEGA5: Molecular Evolutionary Genetics Analysis Using Maximum Likelihood, Evolutionary Distance, and Maximum Parsimony Methods. Molecular Biology and Evolution, 2011; 28: 2731-2739. https://doi.org/10.1093/molbev/msr121

26. Thomas, P.A. and Polwart, A. Taxus baccata L. Journal of Ecology, 2003; 91: 489-524. https://doi.org/10.1046/ j.1365-2745.2003.00783.x

27. Wang, C., Wang, YingJing, Wang, YuJun, Fan, M., Luo, F., and Qian, Z. Characterization, pharmacokinetics and disposition of novel nanoscale preparations of paclitaxel. International Journal of Pharmaceutics, 2011; 414: 251-259. https://doi.org/10.1016/j. ijpharm.2011.05.014

28. Wani, M.C., Taylor, H.L., Wall, M.E., Coggon, P., and McPhail, A.T. Plant Antitumor Agents. VI. The Isolation and Strcture of Taxol, a Novel Antileukemic and Antitumo Agent from Taxus bretvifolia. Journal American Chemical Society, 1971; 2325-2327. https:// doi.org/10.1021/ja00738a045

29. Zein, N., Aziz, S.W., El-sayed, A.S., and Sitohy, B. Comparative cytotoxic and anticancer effect of Taxol derived from Aspergillus terreus and Taxus brevifolia. Bioscience Resaerch, 2019; 16: 1500-1509.

30. Zhang, P., Zhou, P.P., and Yu, L.J. An Endophytic TaxolProducing Fungus from Taxus media, Cladosporium cladosporioides MD2. Current Microbiology, 2009; 59: 227-232. https://doi.org/10.1007/s00284-008-9270-1 